\title{
Contribution of Isoprene Oxidation Products to Marine Aerosol over the North-East Atlantic
}

\author{
Tatu Anttila, ${ }^{1}$ Baerbel Langmann, ${ }^{2}$ Saji Varghese, ${ }^{3}$ and Colin O'Dowd ${ }^{3}$ \\ ${ }^{1}$ Finnish Meteorological Institute, Research and Development, Climate and Global Change, P.O. BOX 503, 00101 Helsinki, Finland \\ ${ }^{2}$ Institute of Geophysics, University of Hamburg, KlimaCampus, Bundesstrasse 55, 20146 Hamburg, Germany \\ ${ }^{3}$ School of Physics, Centre for Climate \& Air Pollution Studies, Environmental Change Institute, National University of Ireland Galway, \\ University Road, Galway, Ireland
}

Correspondence should be addressed to Tatu Anttila, tatu.anttila@fmi.fi

Received 15 February 2010; Revised 14 May 2010; Accepted 21 June 2010

Academic Editor: Olaf Stetzer

Copyright ( $) 2010$ Tatu Anttila et al. This is an open access article distributed under the Creative Commons Attribution License, which permits unrestricted use, distribution, and reproduction in any medium, provided the original work is properly cited.

Secondary organic aerosol (SOA) formation through isoprene oxidation was investigated with the regional-scale climate model REMOTE. The applied modeling scheme includes a treatment for marine primary organic aerosol emissions, aerosol microphysics, and SOA formation through the gas/particle partitioning of semivolatile, water-soluble oxidation products. The focus was on SOA formation taking place over the North-East Atlantic during a period of high biological activity. Isoprene SOA concentrations were up to $\sim 5 \mathrm{ng} \mathrm{m}^{-3}$ over North Atlantic in the base case model runs, and isoprene oxidation made a negligible contribution to the marine organic aerosol (OA) mass. In particular, isoprene SOA did not account for the observed water-soluble organic carbon (WSOC) concentrations over North Atlantic. The performed model calculations, together with results from recent field measurements, imply a missing source of SOA over remote marine areas unless the isoprene oxidation products are considerably less volatile than the current knowledge indicates.

\section{Introduction}

Marine aerosols influence the global climate system directly by scattering incoming solar radiation and indirectly by acting as nuclei on which cloud droplets are formed $[1,2]$. The magnitude of these effects depend on both the physical and chemical properties of marine aerosols. These properties are tied to the aerosol formation mechanisms which can be classified as primary, such as mechanical production driven by wind interactions at the ocean surface, and secondary which refers to gas-to-particle conversion (including heterogeneous reactions) resulting from the gas phase oxidation of volatile compounds [3]. Recently, considerable research effort has been put into characterizing the contribution of organic compounds to the marine aerosol [4-6]. The research has been motivated by the work of O'Dowd et al. [7] who found significant amounts of both water soluble and water insoluble organic aerosol mass in clean marine air. However, the sources of organic carbon are not fully characterized at the present and hence also the relative contributions of primary and secondary processes remain to be evaluated. In this regard, it has been suggested that a potentially important aerosol source is the formation of secondary organic aerosol (SOA) via isoprene oxidation [8].

Several studies have investigated the importance of the SOA formation to the marine aerosol by employing modeling and remote sensing techniques along with laboratory measurements [9-11]. Meskhidze and Nenes [9] suggested that SOA formation resulting from isoprene oxidation affects the cloudiness over oceans even though the authors initially overestimated isoprene emissions. On the other hand, Arnold et al. [10] argued that SOA formation has negligible influence on organic carbon (OC) concentrations over oceans while the results of Gantt et al. [11] show that isoprene SOA may contribute to the submicron marine aerosol mass notably over the tropical oceanic regions. Here it is worth noting that these studies focus on global estimates and also treat the SOA formation in a simplified manner by assuming a constant yield for the secondary organic mass. 
We have addressed the above-mentioned gaps in the current research by employing a regional climate model REMOTE which includes aerosol microphysics and a mechanistic treatment of the isoprene-driven SOA formation. Our goal is to investigate the net and relative contributions of isoprene oxidation products to the marine aerosol mass over the model domain covering Europe and Northern Atlantic in particular. Furthermore, we focus on a high biological activity period from June to August. We also investigate the sensitivity of the results to the current uncertainties in mechanisms underlying isoprene SOA formation.

\section{Methods}

2.1. Model Set-Up. We use the regional three-dimensional on-line climate-chemistry/aerosol model REMOTE (Regional Model with Tracer Extension) [12, 13] with the physical parameterisations of the global ECHAM-4 model [14]. After being released in the atmosphere, gas phase and aerosol phase trace species undergo transport processes (horizontal and vertical advection, transport in convective clouds, vertical turbulent diffusion-for more details see [12]) and are removed from the atmosphere by sedimentation and dry and wet deposition.

For the determination of aerosol dynamics and thermodynamics we use the M7 module, which is described in detail in $[15,16]$. The aerosol dynamical processes in M7 include nucleation, coagulation, and condensation. The aerosol size spectrum is represented by the superposition of seven log-normal distributions subdivided into a soluble and an insoluble coarse, accumulation and Aitken mode, and an additional soluble nucleation mode. The five aerosol components considered in the standard M7 are sulfate (SO4), black carbon (BC), organic carbon (OC), sea salt (SS), and mineral dust (DU). These components have either negligible or low solubility or are treated as an internal mixture of insoluble and soluble compounds. Mixed particles are formed from insoluble particles by coagulation and condensation. Each mode can be described by three moments: aerosol number $N$, number median radius $r$, and standard deviation $\sigma$. Standard deviations are prescribed in M7 [15], so that the median radius of each mode can be calculated from the corresponding aerosol number and aerosol mass, which are transported as 25 tracers.

REMOTE is applied with 19 vertical layers of increasing thickness between the Earth's surface and the $10 \mathrm{hPa}$ pressure level using terrain following hybrid pressure-sigma coordinates. The model domain covers Europe and the North-East Atlantic and is subdivided into $81 \times 91$ grid boxes of $0.5^{\circ}$ resolution (approximately $55 \mathrm{~km}$ ) on a rotated latitude/longitude grid. The model covers an area from about $10^{\circ} \mathrm{W}$ to $30^{\circ} \mathrm{E}$ at the southern boundary of about $30^{\circ} \mathrm{N}$ and from about $40^{\circ} \mathrm{W}$ to $60^{\circ} \mathrm{E}$ in the north at about $70^{\circ}$ $\mathrm{N}$. A model time step of 5 minutes is chosen. REMOTE is initialised at the first time step using meteorological analysis data of the European Centre for Medium Range Weather Forecast (ECMWF), which are updated at the lateral boundaries every 6 hours. Trace species concentration at the lateral boundaries is prescribed and held constant throughout the simulation period.

2.2. Emissions. Anthropogenic emissions obtained from the EMEP emission inventory (http://webdab.emep.int/) are prescribed as monthly fluxes. For coarse mode sea salt, we use the same approach as described in [16] with a table look-up for wind speeds between 1 and $40 \mathrm{~m} / \mathrm{s}$. An organic-inorganic source function for the mixture of POC and sea salt aerosols is used for the net accumulation sea-spray flux [17].

The marine isoprene flux has been estimated dependent on the ocean chlorophyll-a concentration which is used as proxy for the marine biological activity. Based on [9] we assume that the average isoprene seawater concentration in $\mathrm{nM}$ is proportional to chlorophyll-a concentration in $\mathrm{mg} / \mathrm{m}^{3}$ as measured from SeaWiFs. The air-sea flux of isoprene is determined as the product of the isoprene seawater concentration and a gas exchange coefficient according to [18] where the gas exchange coefficient is dependent on $10 \mathrm{~m}$ wind speed and Schmidt number which in turn depends on surface temperature. In addition, terrestrial biogenic terpene and isoprene emissions from forests [12] are considered.

2.3. SOA Formation Scheme. Gas-phase oxidation of isoprene leads to a large number of semivolatile compounds capable of partitioning into the particle phase [8]. Here the semivolatile compounds are lumped into two model compounds $G_{1}$ and $G_{2}$ that represent the high- and lowyield reaction products, respectively. These compounds are produced in the gas phase as follows:

$$
\text { Isoprene }+\mathrm{OH} \longrightarrow \alpha_{1} \mathrm{G}_{1}+\alpha_{2} \mathrm{G}_{2}
$$

where $\alpha_{1}$ and $\alpha_{2}$ are the stoichiometric coefficients for $\mathrm{G}_{1}$ and $G_{2}$, respectively. No other reaction channels are considered because the SOA formation via other channels (e.g., oxidation driven by $\mathrm{O}_{3}$ or $\mathrm{NO}_{3}$ ) is not well characterized at the present [8]. The values of $\alpha_{1}$ and $\alpha_{2}$ are displayed in Table 1 and they were chosen according to the summary of experimental data presented in the recent review [8]. Please note that the values correspond to low $\mathrm{NO}_{\mathrm{x}}$ conditions which reflect the conditions of our study.

The gas/particle partitioning of $G_{1}$ and $G_{2}$ is calculated using Henry's Law equilibrium [19]. This approach was chosen because it is suitable for treating water-soluble compounds and because available information on semivolatile oxidation products of isoprene suggests that many of the compounds are highly water-soluble [8]. Furthermore, marine aerosols contain relatively large amount of water which absorbs soluble compounds [19]. According to Henry's Law, the equilibrium partitioning of a water-soluble compound $X$ between the gas and aqueous phase is given by the following equation:

$$
\mathrm{C}_{X, \mathrm{aq}}=\mathrm{K}_{X}(T) \times \mathrm{C}_{X, \mathrm{gas}},
$$

where $C_{X \text {,aq }}$ and $C_{X \text {,gas }}$ are the aqueous- and gas-phase concentrations of $X$, respectively, $\mathrm{K}_{X}$ is Henry's Law constant for $X$, and $T$ is the temperature. Here it is assumed that $\mathrm{G}_{1}$ 




(a)

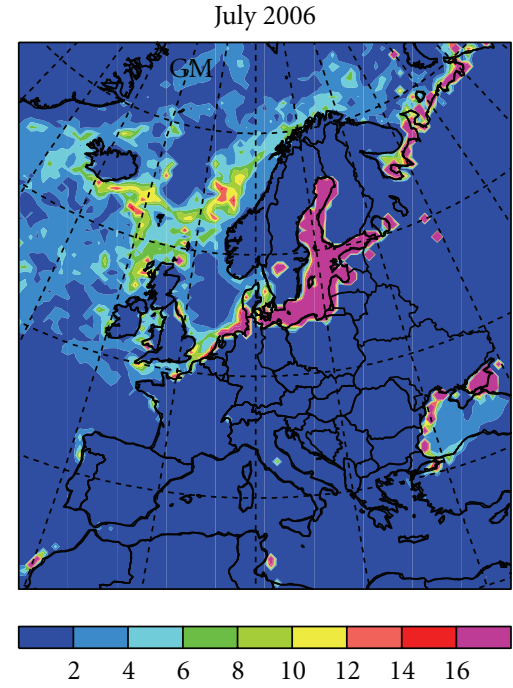

(b)

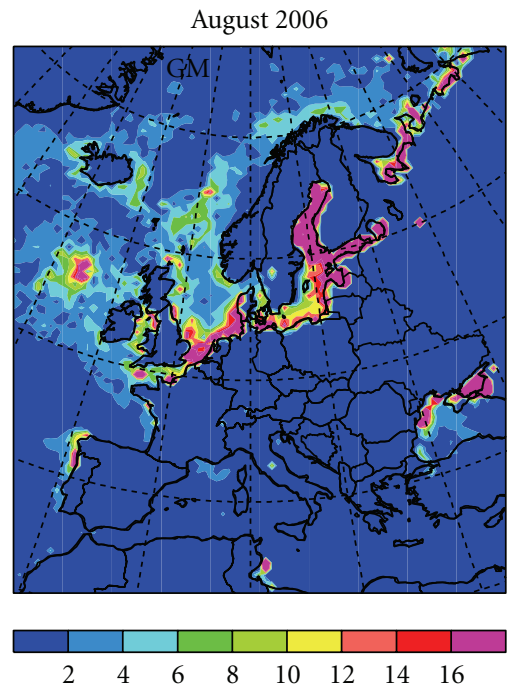

(c)

Figure 1: Monthly averaged marine isoprene fluxes. Latitudes are shown every $10^{\circ}$ from $40^{\circ} \mathrm{N}$ to $70^{\circ} \mathrm{N}$. Longitudes are also shown every $10^{\circ}$ with Greenwhich $\left(0^{\circ}\right)$ indicated with GM in the figures.

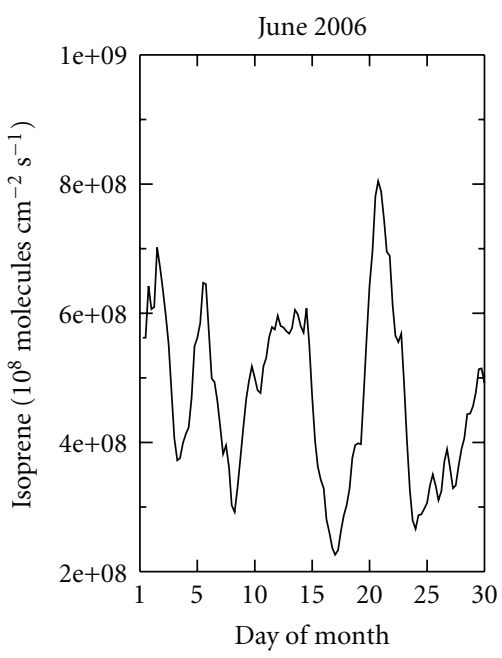

(a)

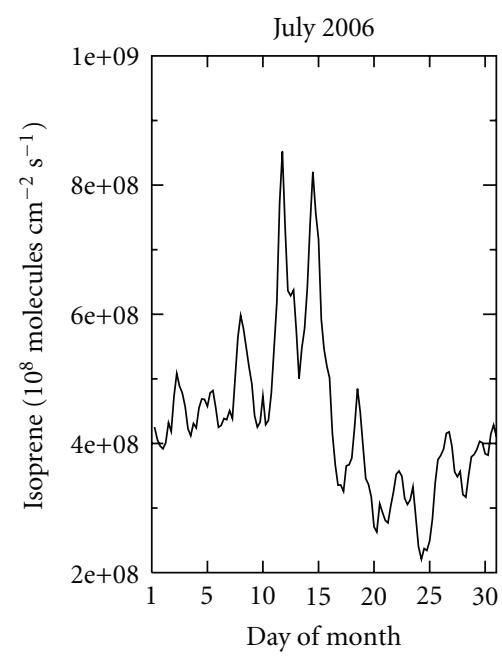

(b)

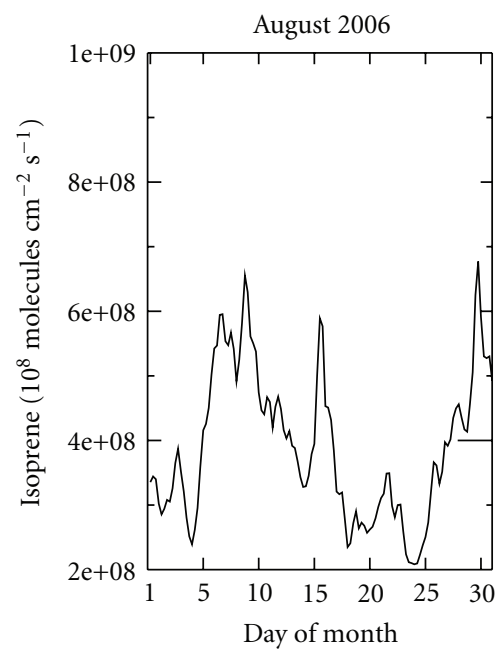

(c)

Figure 2: Time series of isoprene emission fluxes over water. For the areas covered by water, see, for example, Figure 1.

and $\mathrm{G}_{2}$ behave ideally and thus no activity coefficients are introduced into (2). Furthermore, the temperature dependency of Henry's Law constant is accounted for through the Clausius-Clapeyron equation under the assumption that the enthalpy of vaporization for $X, \Delta \mathrm{H}_{X}$, does not depend on the temperature. Finally, the gas/particle partitioning is calculated by neglecting the cloud water as cloud droplet formation is not treated explicitly in the model.

In order to maintain consistency, we have chosen the physicochemical properties of $G_{1}$ and $G_{2}$ using 1,3propanediol and 1,2,4-butanetriol as model compounds. Both of these compounds are highly water-soluble polyols which have been suggested to contribute to the atmospheric SOA [21], and their properties are relatively well known.
Furthermore, polyols are known to form as a result of isoprene oxidation, diols being among the first-generation products while triols result from further oxidation [8]. This is also consistent with $G_{1}$ and $G_{2}$ being the high- and lowyield reaction products, respectively. Table 1 displays the chosen values for the needed physicochemical parameters. Even though the model compounds are less volatile than most of the isoprene oxidation products [8], recent studies have suggested that compounds containing multiple $\mathrm{OH}$ groups (diols, triols, and tetrols, e.g.) contribute substantially to the isoprene SOA [22-24] and therefore $G_{1}$ and $G_{2}$ can be considered as representative of compounds making up the isoprene SOA. For the sake of comparison, the saturation vapour pressures, $\mathrm{P}_{\text {sat }}$, corresponding to Henry's 


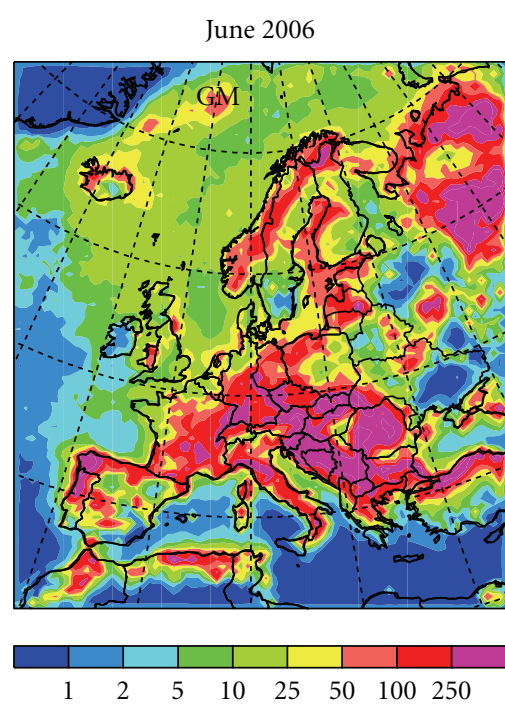

(a)

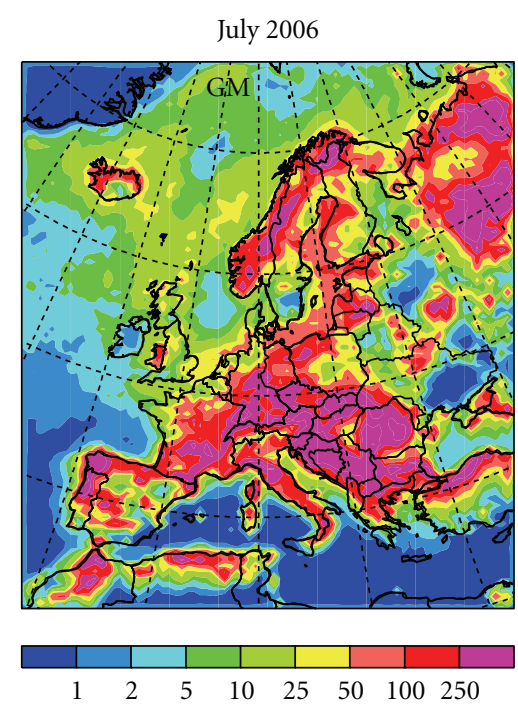

(b)

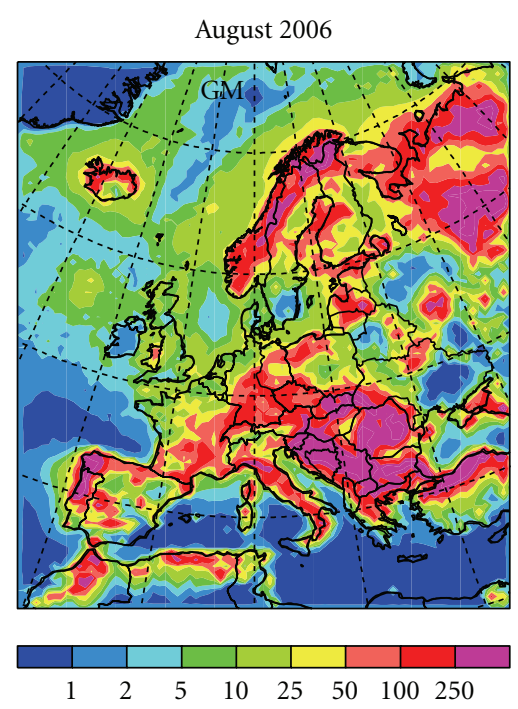

(c)

Figure 3: Monthly mean isoprene surface concentrations over surface for June, July, and August 2006. See caption of Figure 1 for more information about latitudes and longitudes.

TABLe 1: The properties of the semivolatile isoprene oxidation products $G_{1}$ and $G_{2}$. The references are given below the table. Here is $\rho_{i}$ the density of $G_{i}$.

\begin{tabular}{lccccc}
\hline Compound & $\alpha_{i}$ & $\begin{array}{c}M W_{i}{ }^{a} \\
(\mathrm{~g} / \mathrm{mol})\end{array}$ & $\begin{array}{c}\mathrm{K}_{i} \\
(298 \mathrm{~K})^{\mathrm{b}} \\
(\mathrm{M} / \mathrm{atm})\end{array}$ & $\begin{array}{c}\Delta \mathrm{H}_{i} \\
(\mathrm{~kJ} / \mathrm{mol})\end{array}$ & $\begin{array}{c}\rho_{i}{ }^{c} \\
\left(\mathrm{~g} / \mathrm{cm}^{3}\right)\end{array}$ \\
\hline $\mathrm{G}_{1}$ & 0.28 & 76.1 & $9.1 \mathrm{e} 5$ & $72.4^{\mathrm{a}}$ & 1.0 \\
$\mathrm{G}_{2}$ & 0.032 & 106.0 & $3 \mathrm{e} 11$ & $90.0^{\mathrm{c}}$ & 1.0 \\
\hline
\end{tabular}

a Based on data presented in [20].

bSander, R.,1999. http://www.mpch-mainz.mpg.de/ sander/res/henry. html.

${ }^{\mathrm{c}}$ No data were found; estimated on the basis of data presented in [20] for structurally similar compounds.

Law constants of $\mathrm{G}_{1}$ and $\mathrm{G}_{2}$ are around 6.1e-5 and $1.9 \mathrm{e}-10$ atm at $298 \mathrm{~K}$, respectively, assuming ideal conditions at the infinite dilution limit (the equation relating to Henry's Law constant and $\mathrm{P}_{\text {sat }}$ can be found from, e.g., [21]). Conversely, the values for the gas/particle partitioning constants $\mathrm{K}_{\mathrm{om} .1}$ and $\mathrm{K}_{\mathrm{om} .2}$ recommended in [8] for low $\mathrm{NOx}$ conditions would correspond to $\mathrm{P}_{\text {sat }}$ values of around $4.6 \mathrm{e}-8$ and $2.2 \mathrm{e}-$ 10 atm, respectively, at $298 \mathrm{~K}$. The conversion was done by assuming ideal conditions and that the average molecular weight of the organics making up the organic phase is 120 $\mathrm{g} / \mathrm{mol}[25]$.

The SOA formation scheme used here differs from the widely used treatment for SOA formation where the equilibrium partitioning is calculated assuming that the particle-phase organics constitute the absorbing medium rather than water $[8,25]$. In this regard, our approach is complimentary to the previous studies and thus gives new insight to the potential of isoprene oxidation to contribute to the marine SOA formation.
2.4. Extension of M7. It is assumed that aerosols present in any mode containing water can absorb the isoprene oxidation products excluding the nucleation mode. Because isoprene oxidation products were modeled with two compounds, six new aerosol components were thus added to M7 which corresponds to two new compounds present in Aitken, accumulation and coarse modes. Nucleation mode was not included because it makes up only a small fraction of the aerosol volume capable of absorbing semivolatile compounds. Moreover, the amount of isoprene SOA present in each mode is calculated according to the fractional contribution of the mode to the total particle water content.

It is expected that semivolatile isoprene oxidation products, being water-soluble, contribute to the particle water content. This is accounted for by applying the ZSR relation according to which solutes take up water independently of each other [19]. This is also consistent with the treatment of the particle water uptake in M7 [15]. The needed water activity data are taken from the literature [26], and the model compounds for $G_{1}$ and $G_{2}$ were 1,3-propanediol and 1,2,4butanetriol, respectively, consistently with the treatment described in the previous section. In other regards, the new components were treated similarly as the existing aerosol components in M7.

\section{Results}

3.1. Isoprene Fluxes and Surface Concentrations. Monthly mean modeled marine isoprene emission fluxes for June, July, and August 2006 are displayed in Figure 1, and emission time series over water are displayed in Figure 2. As seen, the mean fluxes range between $\sim 10^{8}-10^{9} \mathrm{~cm}^{-2} \mathrm{~s}^{-1}$ over the North-East Atlantic. This range compares well with the modeling and measurement results presented by Palmer and 


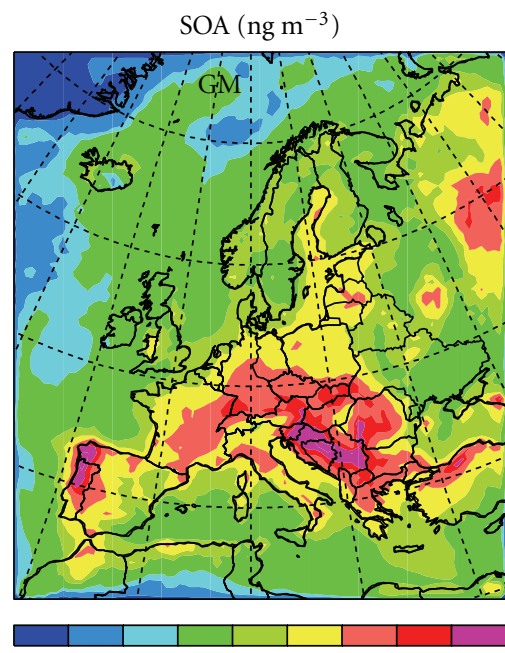

$\begin{array}{llllllll}0.1 & 0.5 & 1 & 5 & 10 & 25 & 50 & 75\end{array}$

(a)

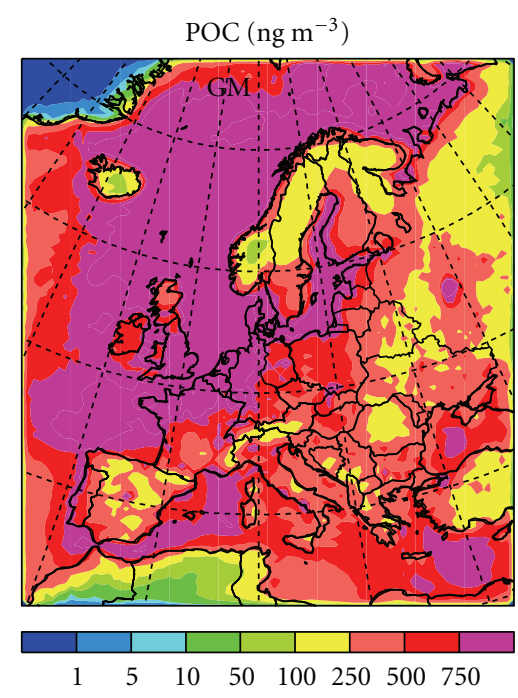

(b)

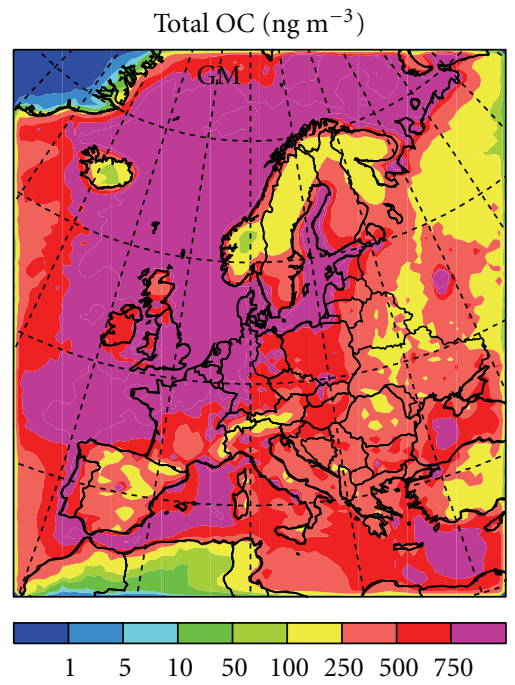

(c)

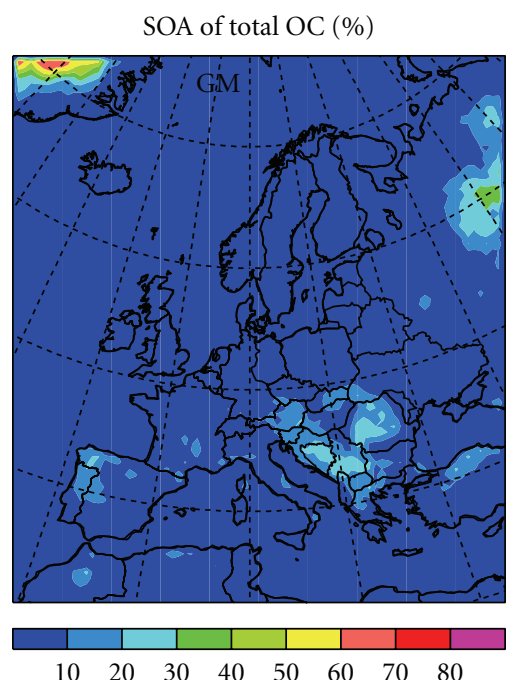

(d)

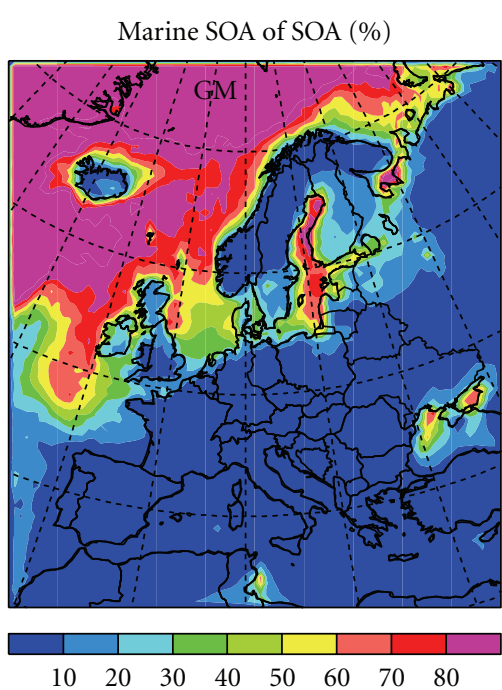

(e)

FIGURE 4: Time-averaged organic aerosol surface concentrations for June 2006. Here "SOA" refers to secondary organic aerosol, "POC" to the primary organic carbon, and "total OC" to the total organic carbon. Also, "\% SOA" refers to the relative contribution of isoprene SOA to the total organic aerosol mass (in percents) and "\% marine SOA of SOA" to the relative contribution of marine SOA to the total SOA (in percents). The relative contributions are derived on the mass basis. See caption of Figure 1 for more information about latitudes and longitudes.

Shaw [18] and Gantt et al. [11]. Figure 2 shows the sixhour average variation of isoprene fluxes over water. The daily variation is mainly caused by variation in the wind speed, and the average fluxes were $4.7 \times 10^{8}, 4.4 \times 10^{8}$, and $3.9 \times 10^{8}$ molecules $\mathrm{cm}^{-2} \mathrm{~s}^{-1}$ for June, July, and August, respectively.

Surface isoprene concentrations, shown in Figure 3, exhibit a considerable contrast in the land/sea distribution with considerably more isoprene over land areas. This is due to differences in biogenic activity, and the contrast is comparable with the results of Arnold et al. [10]. Regarding results for noncoastal marine boundary layer, the isoprene concentrations reach values of up to a few ten ppt while being typically between 1 and 5 ppt which is in agreement with the results of Arnold et al. [10]. Also, comparison of Figures 1 and 3 shows that the isoprene emissions are reflected in the isoprene surface concentrations as expected. Monthly mean surface isoprene concentrations over the NE Atlantic are the highest in June 2006 correlated with the highest chlorophyll-a concentrations during this period. In addition to the chlorophyll-a concentration, wind speed is limiting the isoprene fluxes and hence also the isoprene gas-phase concentrations in particular during August.

\subsection{Marine Organic Carbon: Primary versus Secondary} Sources. Figure 4 shows the monthly mean surface concentrations of SOA, primary organic carbon and total organic carbon (TOC), the relative contribution of SOA to TOC, and 
soalks

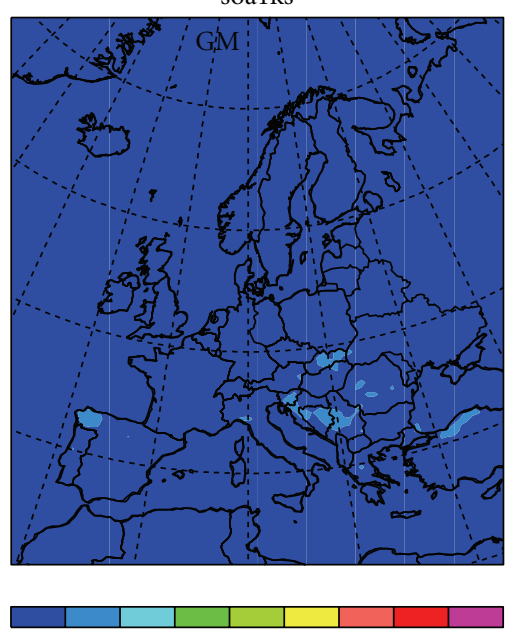

$\begin{array}{llllllll}0.01 & 0.05 & 0.1 & 0.5 & 1 & 5 & 10 & 50\end{array}$

(a)

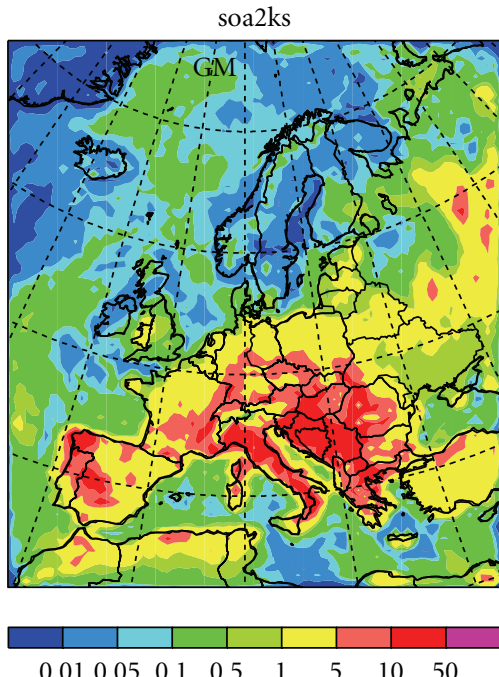

(d)

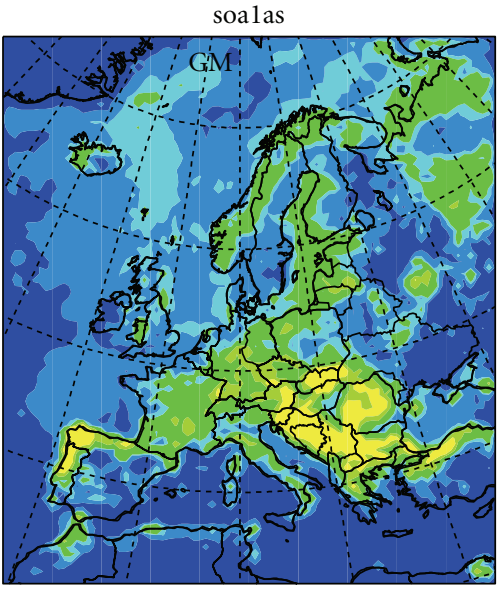

$\begin{array}{llllllll}0.01 & 0.05 & 0.1 & 0.5 & 1 & 5 & 10 & 50\end{array}$

(b)

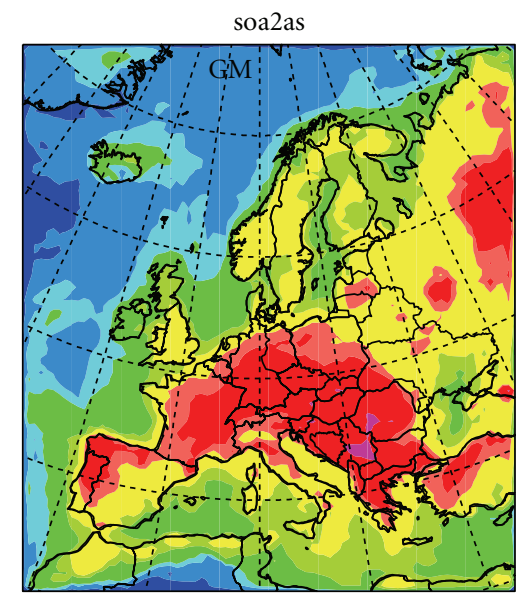

$\begin{array}{llllllll} & & & & & & & \\ 0.01 & 0.05 & 0.1 & 0.5 & 1 & 5 & 10 & 50\end{array}$

(e)

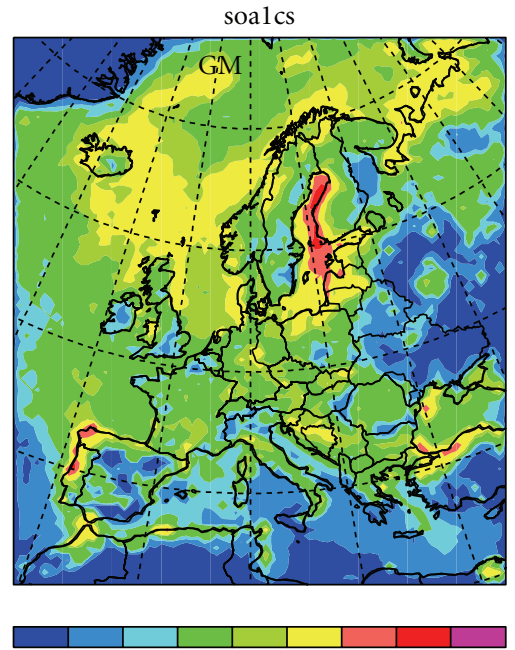

$\begin{array}{llllllll}0.01 & 0.05 & 0.1 & 0.5 & 1 & 5 & 10 & 50\end{array}$

(c)

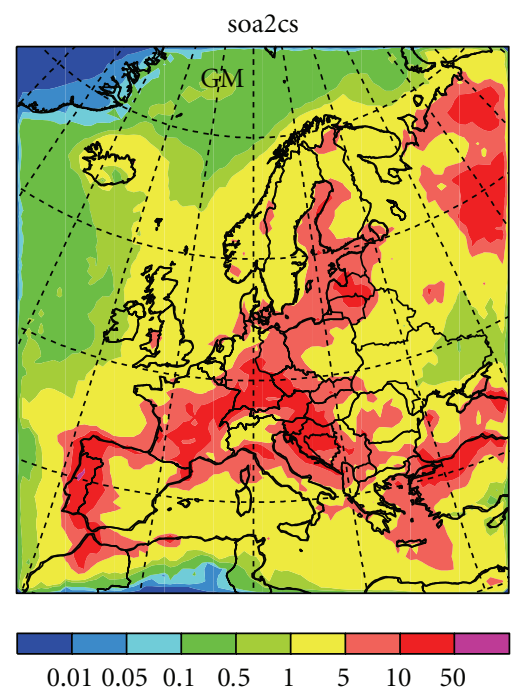

(f)

FIGURE 5: Average particle-phase concentrations over surface of isoprene oxidation products $G_{1}$ (above) and $G_{2}$ (below) for June 2006. The concentrations results are shown separately for Aitken (left), accumulation (middle), and coarse aerosol modes (right). See caption of Figure 1 for more information about latitudes and longitudes.

the relative contribution of marine SOA to the total SOA for June 2006. As seen, isoprene SOA makes only a marginal contribution to the TOC over the remote marine boundary layer, the SOA concentration being up to $\sim 5 \mathrm{ng} \mathrm{m}^{-3}$. SOA comprises thus only $<1 \%$ of the TOC, and a similar estimate was reached also in the study of Arnold et al. [10]. As expected, the highest contribution of marine SOA to the total SOA occurs over ocean water, the contribution of SOA with marine origin being close to $100 \%$ over remote marine areas. Mode-fractionated aerosol-phase concentrations of $\mathrm{G}_{1}$ and $\mathrm{G}_{2}$ in Aitken, accumulation and coarse modes are shown in Figure 5 for June 2006. A comparison of the contributions of $G_{1}$ and $G_{2}$ reveals that the less volatile $G_{2}$ accounts for most of the simulated SOA mass despite the lower stoichiometric yield (see Table 1). Over remote marine areas, largest SOA concentrations are found generally in the coarse mode because the mode contains largest concentration of particulate water (not shown here). The submicron SOA concentrations remain below one $\mathrm{ng} \mathrm{m}^{-3}$ over North Atlantic; that is, the contribution of isoprene oxidation to submicron aerosol mass is negligible.

The measured WSOC concentrations of North Atlantic marine aerosols ranged between $\sim 0.1-0.15 \mu \mathrm{gC} \mathrm{m}^{-3}$ during the summer months [5]. Using a ratio of 2.1 for the average organic molecular weight per carbon weight [27], the maximum modeled isoprene SOA concentrations over North-East Atlantic (around $5 \mathrm{ng} \mathrm{m}^{-3}$ see above) were around $2.4 \mathrm{ngC} \mathrm{m}^{-3}$. Keeping in mind that the primary organic aerosol is treated as insoluble whereas SOA is assumed to be entirely water-soluble in the model, it can be 


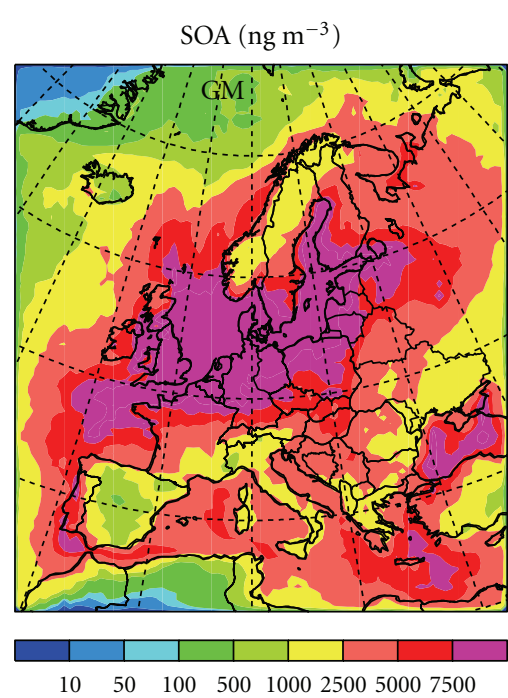

(a)

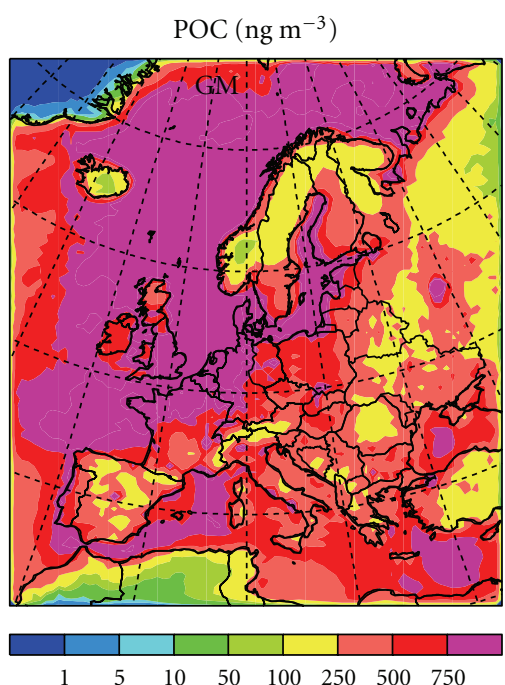

(b)

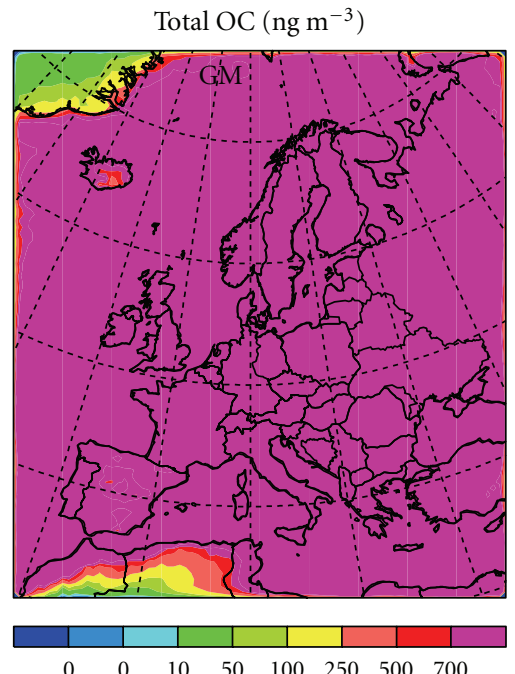

(c)

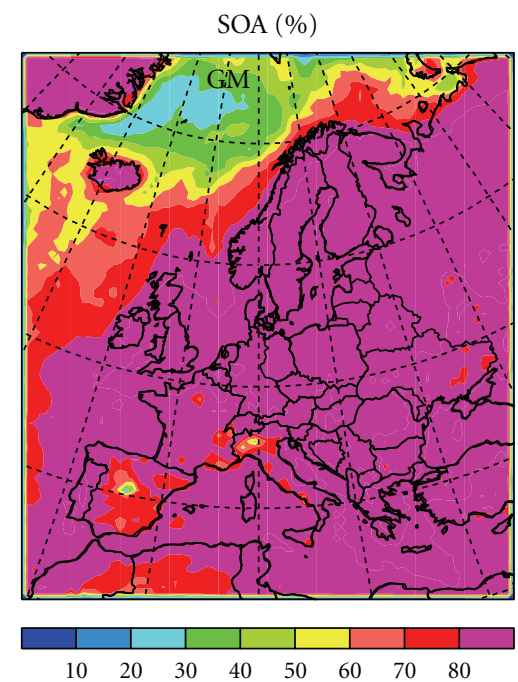

(d)

Figure 6: Time-averaged organic aerosol surface concentrations for June 2006 with $\mathrm{K}_{1}=9.1 \mathrm{e} 6 \mathrm{M} / \mathrm{atm}$. Here "SOA" refers to secondary organic aerosol, "POC" to the primary organic carbon, and "total OC" to the total organic carbon. Also, "\% SOA" refers to the relative contribution of isoprene SOA to the total organic aerosol mass (in percents). The relative contribution is derived on the mass basis. See caption of Figure 1 for more information about latitudes and longitudes.

thus concluded that isoprene SOA cannot account for the observed WSOC concentrations. Moreover, recent studies of Ceburnis et al. [28] and Facchini et al. [6] suggest that marine WIOC is mainly of primary origin and that WSOC originates mainly from secondary sources. Consequently, the performed simulations suggest that SOA formation resulting from isoprene oxidation does not explain the observed WSOC concentrations, but other secondary sources need to be investigated.

As further seen from Figure 4, TOC concentrations were around $1 \mu \mathrm{g} \mathrm{m}^{-3}$ over the North Atlantic. Using the abovementioned conversion factor, this would correspond to TOC concentrations of around $0.48 \mu \mathrm{gC} \mathrm{m}^{-3}$. This can be compared with the measurement results from the Mace Head station according to which TOC concentrations varied between $\sim 0.4-0.6 \mu \mathrm{gC} \mathrm{m}^{-3}$ for the period from June to August [29]. To conclude with, the model reproduces the observed TOC concentrations relatively well but underestimates the observed contribution of WSOC to the marine aerosol.

3.3. Sensitivity Studies. Key model parameters in determining the amount of SOA formed are Henry's Law constants for the oxidation products G1 and G2, K1 and K2, respectively (see Section 2.3). Given the current uncertainties in isoprene SOA formation, we repeated the above-described model simulations with increased values of $K_{1}$ and $K_{2}$ at $298 \mathrm{~K}$ in order to investigate whether increased partitioning of $G_{1}$ and $G_{2}$ into the particle phase may alter the conclusions 


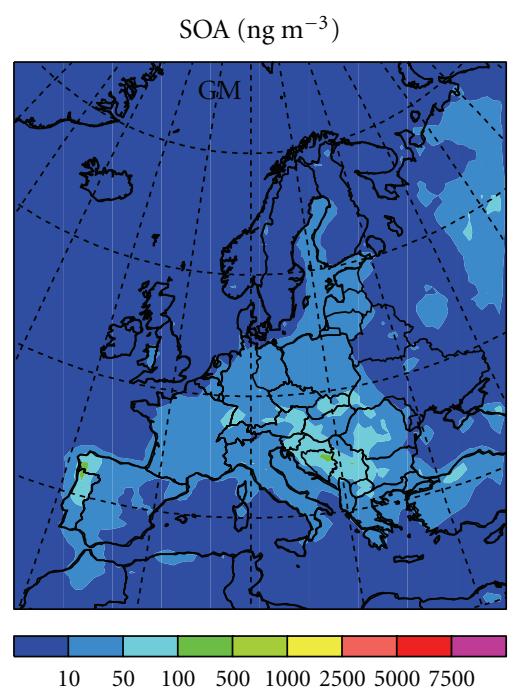

(a)



(b)

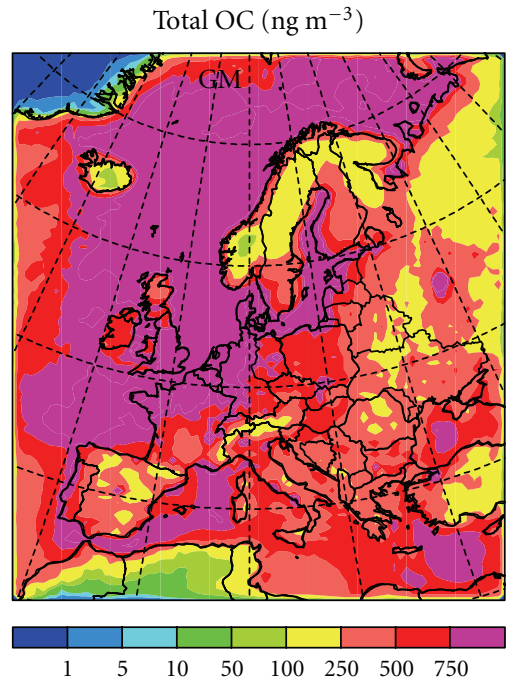

(c)

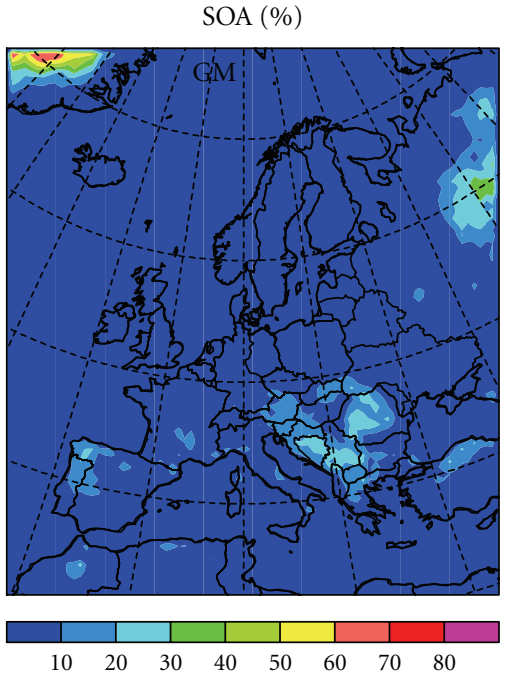

(d)

Figure 7: Same as Figure 6 but for the model runs with $K_{2}=3 e 11 \mathrm{M} / \mathrm{atm}$.

based on the base case simulations. Here the focus was on marine SOA concentrations close to the surface level. As in the base simulations, the main source of marine SOA was mainly isoprene oxidation taking place over oceans rather than oxidation of terrestrial emissions (not shown). In the first sensitivity run, the value of $\mathrm{K}_{1}$ was increased by an order of magnitude (Figure 6). As seen, the increased partitioning of $\mathrm{G}_{1}$ leads to considerable increases in the isoprene SOA masses such that isoprene SOA accounts for up to $\sim 80$ $90 \%$ of the total organic aerosol mass over North Atlantic. In the second sensitivity run, the value of $\mathrm{K}_{2}$ was increased by an order of magnitude (Figure 7 ). Because $\mathrm{G}_{2}$ is produced with smaller yield in the gas phase (Table 1), increased partitioning into the aerosol phase does not lead to notable increases in the SOA concentrations. Even though $\mathrm{G}_{2}$ made dominant contribution to the isoprene SOA in the base case simulations, the results are more sensitive to the properties of more volatile compound $\mathrm{G}_{1}$. Accordingly, the contribution of isoprene SOA to the marine organic carbon is sensitive to the amount of semivolatile reaction products that are formed with relatively large yield.

\section{Summary and Conclusions}

Contribution of isoprene oxidation products to the marine organic aerosol was investigated with a regional climate model REMOTE. The aerosol microphysics module of REMOTE, M7, was extended to treat gas/particle partitioning of semivolatile, water-soluble isoprene oxidation products. Here it is worth noting that the applied isoprene SOA formation scheme differs from those applied in the previous studies where the semivolatile reaction products were assumed to partition into the particle organic phase 
rather than into the aqueous phase. Furthermore, the focus was on SOA formation taking place over the North-East Atlantic during a period of high biological activity.

Isoprene SOA concentrations were up to $\sim 5 \mathrm{ng} \mathrm{m}^{-3}$ over North Atlantic in the base case model runs, and the SOA was formed almost entirely over water. Isoprene oxidation made a negligible contribution to the marine organic aerosol (OA) mass. In particular, isoprene SOA did not account for the observed concentrations of water-soluble organic carbon (WSOC) over North Atlantic. The performed model calculations, together with results from recent field measurements, imply a missing source of WSOC over remote marine areas unless the isoprene oxidation products are considerably less volatile than the current knowledge indicates. A possible source is also conversion of water-insoluble compounds into WSOC through heterogeneous reactions taking place in the aqueous phase of particles and cloud droplets $[29,30]$. In order to elucidate the origin of WSOC in marine aerosols, isoprene oxidation mechanisms in both the gas and aerosol phase need to be elucidated further along with investigating the potential of other volatile organic compounds (such as monoterpenes; see, e.g., [31]) to form SOA over marine areas.

\section{Acknowledgments}

The authors would like to acknowledge Environmental Protection Agency of Ireland, Enterprise Ireland, and the European Commission (MAP project, http://macehead.nuigalway .ie/map). One of the authors (T. Anttila) acknowledges financial support from the ACCENT network (Atmospheric Composition Change-European Network of Excellence, http://www.accent-network.org/) and from the Emil Aaltonen Foundation.

\section{References}

[1] S. Twomey, "Aerosols, clouds and radiation," Atmospheric Environment, Part A, vol. 25, no. 11, pp. 2435-2442, 1991.

[2] U. Lohmann and J. Feichter, "Global indirect aerosol effects: a review," Atmospheric Chemistry and Physics, vol. 5, no. 3, pp. 715-737, 2005.

[3] C. D. O'Dowd and G. De Leeuw, "Marine aerosol production: a review of the current knowledge," Philosophical Transactions of the Royal Society A, vol. 365, no. 1856, pp. 1753-1774, 2007.

[4] F. Cavalli, M. C. Facchini, S. Decesari et al., "Advances in characterization of size-resolved organic matter in marine aerosol over the North Atlantic," Journal of Geophysical Research D, vol. 109, no. 24, Article ID D24215, 14 pages, 2004.

[5] Y. J. Yoon, D. Ceburnis, F. Cavalli et al., "Seasonal characteristics of the physicochemical properties of North Atlantic marine atmospheric aerosols," Journal of Geophysical Research D, vol. 112, no. 4, Article ID D04206, 2007.

[6] M. C. Facchini, M. Rinaldi, S. Decesari et al., "Primary submicron marine aerosol dominated by insoluble organic colloids and aggregates," Geophysical Research Letters, vol. 35, no. 17, Article ID L17814, 2008.

[7] C. D. O’Dowd, M. C. Facchini, F. Cavalli et al., "Biogenically driven organic contribution to marine aerosol," Nature, vol. 431, no. 7009, pp. 676-680, 2004.
[8] A. G. Carlton, C. Wiedinmyer, and J. H. Kroll, "A review of Secondary Organic Aerosol (SOA) formation from isoprene," Atmospheric Chemistry and Physics, vol. 9, no. 14, pp. 49875005, 2009.

[9] N. Meskhidze and A. Nenes, "Phytoplankton and cloudiness in the southern ocean," Science, vol. 314, no. 5804, pp. 14191423, 2006.

[10] S. R. Arnold, D. V. Spracklen, J. Williams et al., "Evaluation of the global oceanic isoprene source and its impacts on marine organic carbon aerosol," Atmospheric Chemistry and Physics, vol. 9, no. 4, pp. 1253-1262, 2009.

[11] B. Gantt, N. Meskhidze, and D. Kamykowski, "A new physically-based quantification of marine isoprene and primary organic aerosol emissions," Atmospheric Chemistry and Physics, vol. 9, no. 14, pp. 4915-4927, 2009.

[12] B. Langmann, "Numerical modelling of regional scale transport and photochemistry directly together with meteorological processes," Atmospheric Environment, vol. 34, no. 21, pp. 3585-3598, 2000.

[13] B. Langmann, S. Varghese, E. Marmer et al., "Aerosol distribution over Europe: a model evaluation study with detailed aerosol microphysics," Atmospheric Chemistry and Physics, vol. 8, no. 6, pp. 1591-1607, 2008.

[14] E. Roeckner, K. Arpe, L. Bengtsson, et al., "The atmospheric general circulation model ECHAM-4: model description and simulation of present-day climate," Tech. Rep. 218, Max Planck Institute for Meteorology, Hamburg, Germany, 1996.

[15] E. Vignati, J. Wilson, and P. Stier, "M7: an efficient sizeresolved aerosol microphysics module for large-scale aerosol transport models," Journal of Geophysical Research D, vol. 109, no. 22, Article ID D22202, 17 pages, 2004.

[16] P. Stier, J. Feichter, S. Kinne et al., "The aerosol-climate model ECHAM5-HAM," Atmospheric Chemistry and Physics, vol. 5, no. 4, pp. 1125-1156, 2005.

[17] E. Vignati, M. C. Facchini, M. Rinaldi et al., "Global scale emission and distribution of sea-spray aerosol: sea-salt and organic enrichment," Atmospheric Environment, vol. 44, no. 5, pp. 670-677, 2010.

[18] P. I. Palmer and S. L. Shaw, "Quantifying global marine isoprene fluxes using MODIS chlorophyll observations," Geophysical Research Letters, vol. 32, no. 9, Article ID GL022592, 5 pages, 2005.

[19] J. H. Seinfeld and S. N. Pandis, Atmospheric Chemistry and Physics: From Air Pollution to Climate Change, John Wiley \& Sons, New York, NY, USA, 1998.

[20] J. A. Dean, Lange's Handbook on Chemistry, McGraw-Hill, New York, NY, USA, 13th edition, 1985.

[21] P. Saxena and L. M. Hildemann, "Water-soluble organics in atmospheric particles: a critical review of the literature and application of thermodynamics to identify candidate compounds," Journal of Atmospheric Chemistry, vol. 24, no. 1, pp. 57-109, 1996.

[22] M. Claeys, B. Graham, G. Vas et al., "Formation of secondary organic aerosols through photooxidation of isoprene," Science, vol. 303, no. 5661, pp. 1173-1176, 2004.

[23] E. O. Edney, T. E. Kleindienst, M. Jaoui et al., "Formation of 2methyl tetrols and 2-methylglyceric acid in secondary organic aerosol from laboratory irradiated isoprene $/ \mathrm{NO}_{X} / \mathrm{SO}_{2} /$ air mixtures and their detection in ambient $\mathrm{PM}_{2.5}$ samples collected in the eastern United States," Atmospheric Environment, vol. 39, no. 29, pp. 5281-5289, 2005.

[24] I. Kourtchev, T. Ruuskanen, W. Maenhaut, M. Kulmala, and M. Claeys, "Observation of 2-methyltetrols and related photooxidation products of isoprene in boreal forest aerosols from 
Hyytiälä, Finland," Atmospheric Chemistry and Physics, vol. 5, no. 10, pp. 2761-2770, 2005.

[25] J. F. Pankow, "An absorption model of the gas/aerosol partitioning involved in the formation of secondary organic aerosol," Atmospheric Environment, vol. 28, no. 2, pp. 189-193, 1994.

[26] C. Marcolli and T. Peter, "Water activity in polyol/water systems: new UNIFAC parameterization," Atmospheric Chemistry and Physics, vol. 5, no. 6, pp. 1545-1555, 2005.

[27] B. J. Turpin and H.-J. Lim, "Species contributions to PM2.5 mass concentrations: revisiting common assumptions for estimating organic mass," Aerosol Science and Technology, vol. 35, no. 1, pp. 602-610, 2001.

[28] D. Ceburnis, C. D. O’Dowd, G. S. Jennings et al., "Marine aerosol chemistry gradients: elucidating primary and secondary processes and fluxes," Geophysical Research Letters, vol. 35, no. 7, Article ID L07804, 2008.

[29] H.-J. Lim, A. G. Carlton, and B. J. Turpin, "Isoprene forms secondary organic aerosol through cloud processing: model simulations," Environmental Science and Technology, vol. 39, no. 12, pp. 4441-4446, 2005.

[30] A. Limbeck, M. Kulmala, and H. Puxbaum, "Secondary organic aerosol formation in the atmosphere via heterogeneous reaction of gaseous isoprene on acidic particles," Geophysical Research Letters, vol. 30, no. 19, Article ID GL017738, 6 pages, 2003.

[31] N. Yassaa, I. Peeken, E. Zöllner et al., "Evidence for marine production of monoterpenes," Environmental Chemistry, vol. 5, no. 6, pp. 391-401, 2008. 

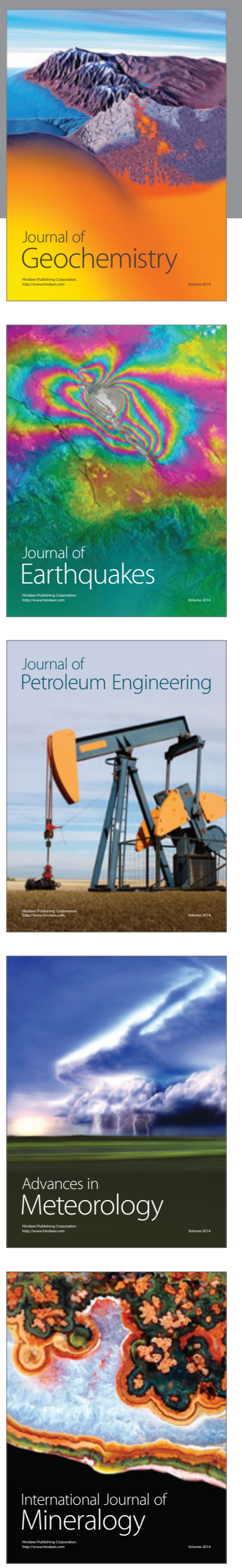
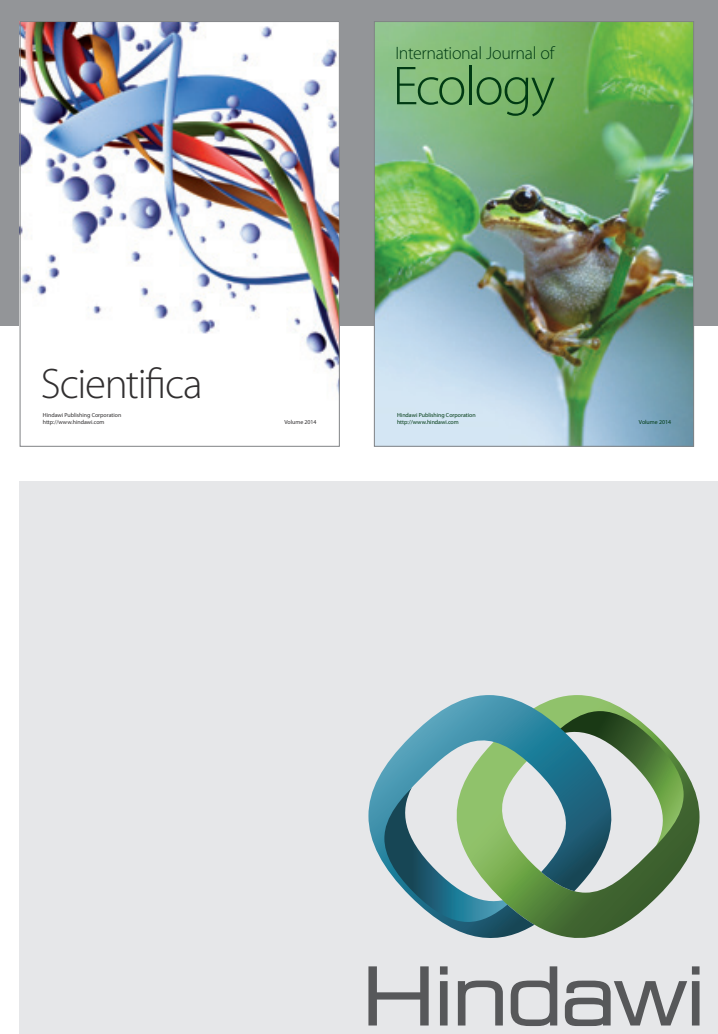

Submit your manuscripts at http://www.hindawi.com
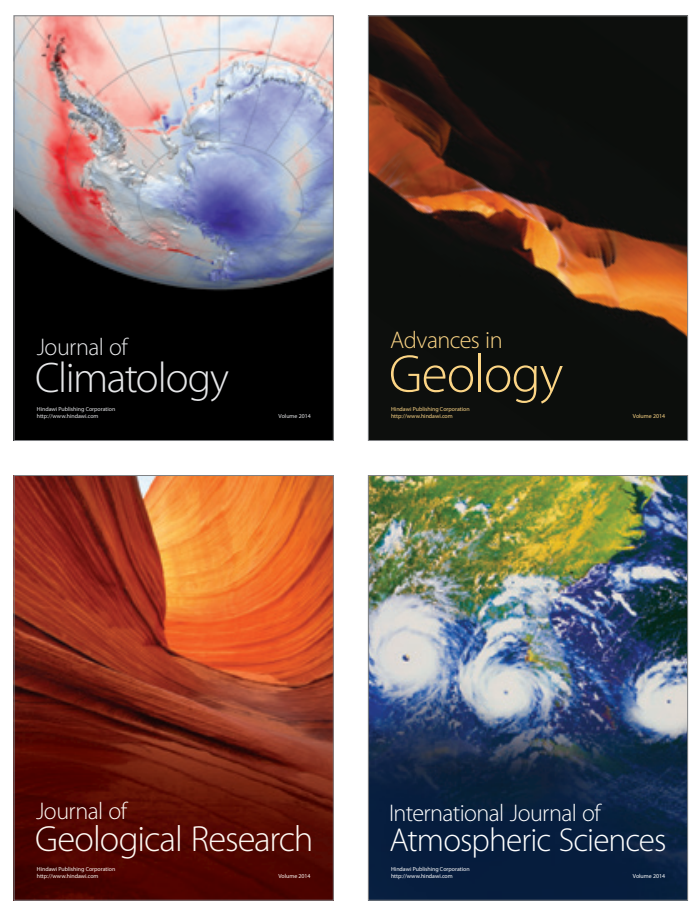
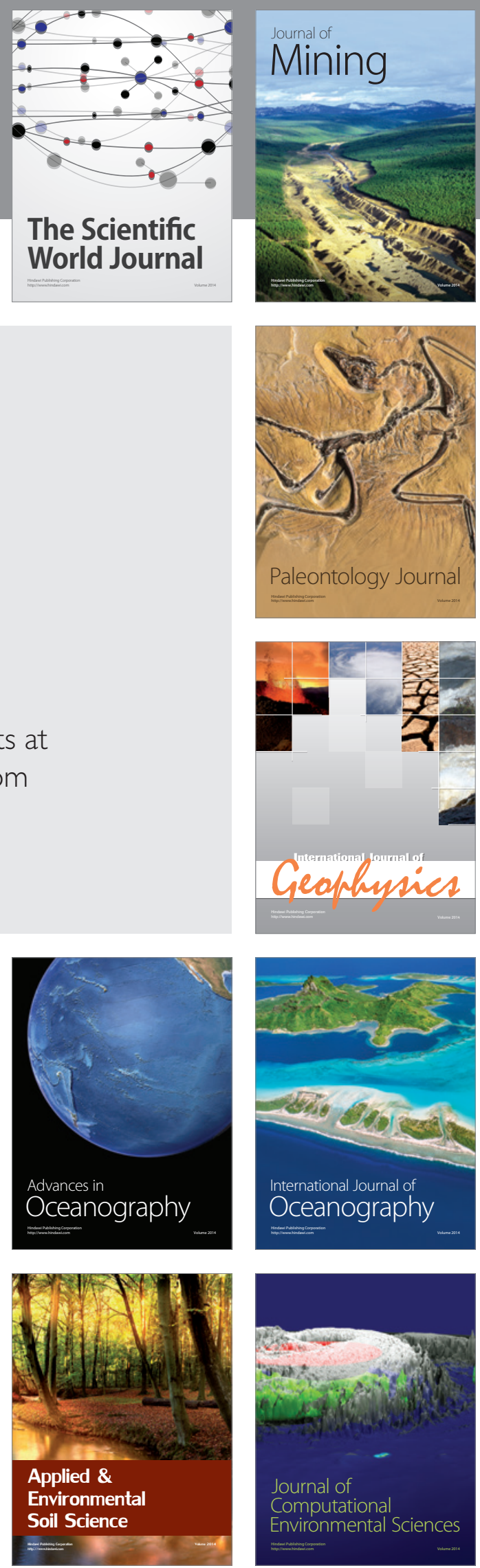